\title{
Modelling Trickle Irrigation: Comparison of Analytical and Numerical Models For Estimation of Wetting Front Position with Time.
}

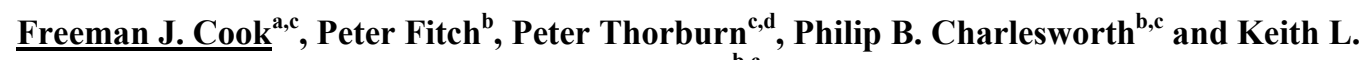 \\ Bristow $^{\text {b,c }}$
}

${ }^{\mathrm{a}}$ CSIRO Land and Water, 120 Meiers Road, Indooroopilly, QLD 4068, Australia freeman.cook@csiro.au, ${ }^{\mathrm{b}} \mathrm{CSIRO}$ Land and Water, PMB Aitkenvale, Townsville, QLD 4814, Australia, ${ }^{\mathrm{c}} \mathrm{CRC}$ for Sustainable Sugar Production and ${ }^{\mathrm{d}}$ CSIRO sustainable Ecosystems, 120 Meiers Road, Indooroopilly, QLD 4068, Australia

\begin{abstract}
Irrigation practices that are profligate in their use of water have come under closer scrutiny by water managers and the public. Trickle irrigation has the propensity to increase water use efficiency but only if the system is designed to meet the soil and plant conditions. Recently we have provided a software tool, WetUp, to calculate the wetting patterns from trickle irrigation emitters. WetUp uses an analytical solution to calculate the wetted perimeter for both buried and surface emitters. This analytical solution has a number of assumptions, one of which is that the hydraulic conductivity (k) at the wetting front is a specific value. Here we compare the wetting patterns calculated with a 2dimensional numerical model, HYDRUS2D, for solving the flow into typical soils with the analytical solution. The results show that the wetting patterns are similar. Difficulties were experienced with getting stable solutions with HYDRUS2D for soils with low hydraulic conductivities.
\end{abstract}

Keywords: Trickle irrigation; wetting patterns; numerical modelling; analytical modelling

\section{Introduction}

Water allocation is a topical issue in Australia due to increasing competition between urban, rural, industrial and environmental users. Irrigation practices are therefore coming under closer scrutiny and there will be a requirement for more efficient irrigation practices. One of the methods that can provide high water use efficiency is trickle irrigation, but only if designed correctly ie. emitter spacing, flow rate and depth of installation (Phene, 1995). The Burdekin region is presently furrow irrigated which can result in considerable losses of water from the root system to depth (Charlesworth et al., 2002). This drainage water in part contributes to recharging of the groundwater aquifer (Bristow et al., 2002), which is suffering seawater intrusion problems. The move to more efficient irrigation could exacerbate these problems. Thus if trickle irrigation is to be used, the wetting patterns of trickle emitters will need to be estimated. Also, the whole of system effects of any major changes in irrigation practices need to be assessed (eg. marked change in groundwater recharge).

Modelling of water flow from surface or buried emitters is an axi-symetrical flow problem. This problem can be solved both analytically, with certain assumptions, and numerically.

Analytical models provide a rapid method for determining the wetting front position (Revol et al., 1997; Thorburn, et al., 2003; Cook et al., 2003). These models are based on the assumption of a point source and certain forms for the physical properties of soil and water content distributions (Philip, 1984; Revol et al., 1997). Recently the WetUp model, based on such a relationship, was developed and released for irrigators to use.

Numerical models have fewer assumptions but require considerable computing power. These models also have assumptions built into them and there is some 'art' to using them. Here we will use the finite element HYDRUS2D model (Simunek et al., 1999) to simulate the flow from buried and surface emitters. Previous work with this model (Cote et al., 2003) has shown that useful results can be obtained.

Here we will compare the results from analytical and numerical models on prediction of the wetting front. We show that the analytical models give reasonably good estimates of the wetting front position. Hence 
models such as WetUp, which uses such relationships as the basis for their predicted wetting front position, can provide reliable estimates when designing trickle irrigation systems.

\subsection{Theory}

Consider a field that is irrigated by a set of emitters spaced at regular intervals, $2 R$, at either the surface or buried at depth $Z_{e}$. Due to the symmetry of the emitter layout, and assuming that each emitter discharges water at the same flow rate, a one-hectare field can be subdivided into identical volume elements of length and width $2 R$ and depth $Z$, with a trickle emitter placed at either the surface or depth $Z_{e}$ on the plane of symmetry. It is assumed that the trickle emitter can be represented as a small sphere of radius $\rho$ [L]. In order to describe water patterns in an entire field, it is sufficient to analyse the flow in this single volume element. Because of the symmetry around the vertical axis, the infiltration process can be viewed as an axi-symmetrical flow, with the radius $s[\mathrm{~L}]$ and the depth $z$ [L] as key variables. Here we analyse this problem using both an analytical model and numerical model.

\subsection{Analytical Model}

In developing the theory we consider a source of strength $\mathrm{Q}\left[\mathrm{L}^{3} \mathrm{~T}^{-1}\right]$ located at $(s, z)=(0,0)$. The radial distance in the plane of the source $(z$ $=0)$ and the maximum vertical distance $(s=0)$ are described by Thorburn et al. (2003) and are not repeated here. For a buried source, the distance to the wetted perimeter at dimensionless time, $T$, is given by equation (30) of Philip (1984):

$$
\begin{aligned}
& T(R, \phi)=\frac{\exp \left(2 R \sin ^{2} \frac{1}{2} \phi\right)}{2 \cos ^{2} \frac{1}{2} \phi} \\
& \left\{\begin{array}{l}
R^{2}-R+\left[\ln \left(\cos \frac{1}{2} \phi\right)-R \sin ^{2} \frac{1}{2} \phi+\frac{1}{2}\right] \\
\cdot \ln \left(\frac{\exp \left[2 R \sin ^{2} \frac{1}{2} \phi\right]-\cos ^{2} \frac{1}{2} \phi}{\sin ^{2} \frac{1}{2} \phi}\right) \\
-\frac{1}{2}\left[L\left(\sec ^{2} \frac{1}{2} \phi \exp \left[2 R \sin ^{2} \frac{1}{2} \phi\right]\right)-L\left(\sec ^{2} \frac{1}{2} \phi\right)\right]
\end{array}\right\} \\
& 0<\phi<\pi
\end{aligned}
$$

where $r, \phi$ are the spherical polar coordinates $(s=r \sin \phi, z=r \cos \phi), R=\alpha r / 2, \alpha$ is the reciprocal of the macroscopic capillary length scale (White and Sully, 1987), $L(\mathrm{x})$ is the dilogarithm defined by:

$$
L(x)=-\int_{1}^{x} \frac{\ln x}{x-1} d x
$$

where $x$ is a dummy variable and the dimensionless time $T$ is given by:

$$
T=\frac{\alpha^{3} Q t}{16 \pi \Delta \theta}
$$

where $Q$ is the dripper flow rate, $t$ is time and $\Delta \theta$ is the average change in volumetric water content behind the wetting front (Revol et al., 1997; Cook et al., 2003) and $\alpha$ is the reciprocal of the macroscopic capillary length scale. The macroscopic capillary length scale is a hydraulic conductivity weighted scaling factor that relates the matric potential to the hydraulic conductivity (Philip, 1985), and can be thought of as the "mean" height of capillary rise above a water table (Raats and Gardner, 1971).

For a surface source, $T$ is related to the wetted perimeter by eqn (44) of Philip (1984):

$$
\begin{aligned}
& T(R, \phi),=\exp [R(1-\cos \phi)] \\
& \left\{\begin{array}{l}
R^{2}\left(1-\frac{1}{2} \cos \phi\right)-R+ \\
\frac{1}{\cos \phi}\left[\begin{array}{l}
R(1-\cos \phi) \ln (1-\cos \phi) \\
+\ln \left(\frac{1-\cos \phi \exp [R(\cos \phi-1)]}{1-\cos \phi}\right) \\
-L(1-\cos \phi \exp [R(\cos \phi-1)])+L(1-\cos \phi)
\end{array}\right]
\end{array}\right. \\
& 0<\phi<\frac{1}{2} \pi
\end{aligned}
$$

Equations (1) and (4) were solved to give values of $R, \phi$ for set values of $T$, using programs written in Maple 7 (Waterloo Maple, 2000). The solution method was to use a binary splitting procedure until the relative difference ((LHS-RHS)/LHS) between the LHS and RHS of eqns (1) and (4) was less that $1 \times 10^{-6}$.

\subsection{Numerical Model}

Three-dimensional axi-symmetrical flow in variably saturated, rigid, isotropic porous media can be described by the following modified form of Richards' equation

$$
\begin{gathered}
\frac{\partial \theta}{\partial t}=\frac{\partial}{\partial s}\left(K(h) \frac{\partial h}{\partial s}\right)+\frac{K(h)}{s} \frac{\partial h}{\partial s} \\
+\frac{\partial}{\partial z}\left(K(h)\left[\frac{\partial h}{\partial z}+1\right]\right)
\end{gathered}
$$

where $\theta\left[\mathrm{L}^{3} \mathrm{~L}^{-3}\right]$ is the volumetric water content, $h[\mathrm{~L}]$ is the pressure head, $t[\mathrm{~T}]$ is time, $s[\mathrm{~L}]$ is the radial coordinate, $z[\mathrm{~L}]$ is the vertical coordinate taken positive upwards, and $K \quad\left[\mathrm{LT}^{-1}\right]$ is the unsaturated hydraulic conductivity. In this study, Eq.(5) is solved 
numerically using HYDRUS2D (Simunek et al., 1999) with initial and boundary conditions that closely reproduce trickle irrigation systems (see Materials and Methods).

\section{Materials and Methods}

\subsection{Soil Hydraulic Properties}

The analytical solution is based on an exponential model for hydraulic conductivity (k) first proposed by Gardner (1956):

$$
k=K_{s} \exp (\alpha \psi)
$$

where $K_{s}$ is the saturated hydraulic conductivity $\left[\mathrm{Lr} \mathrm{T}^{-1}\right]$ and $\psi$ is the matric potential [L]. Unfortunately this model cannot be used in HYDRUS2D at the moment, so a direct comparison of the analytical and numerical is not possible.

In HYDRUS2D we used the Brooks and Corey (1966) model for the moisture characteristic and hydraulic conductivity (with modifications due to Campbell (1974)):

$$
\frac{\theta}{\theta_{s}}=S e=\left(\frac{\psi}{\psi_{s}}\right)^{-1 / b}
$$

and

$$
k=K_{s} S e^{(2 b+3)}
$$

where $\psi_{s}$ is the air-entry potential of the soil.

Equations (7) and (8) were used to define the water content at the wetting front $\left(\theta_{w}\right)$ for calculation of $\Delta \theta$ as described in Thorburn et al. (2003). The value of $\theta_{w}$ was arbitrarily chosen as the water content at which $k$ given by eqn (8) was $1 \mathrm{~mm} \mathrm{day}^{-1}$.

Table 1. Soil physical data for soils in this study.

\begin{tabular}{llll}
\hline Property & Sand & Clay & BB10 \\
\hline$\theta_{s}\left(\mathrm{~m}^{3} \mathrm{~m}^{-3}\right)$ & 0.395 & 0.482 & 0.433 \\
$\psi_{s}(\mathrm{~m})$ & -0.12 & -0.41 & -0.05 \\
$K_{s}\left(\mathrm{~m} \mathrm{~s}^{-1}\right)$ & $1.76 \mathrm{e}^{-4}$ & $1.28 \mathrm{e}^{-6}$ & $2.38 \mathrm{e}^{-4}$ \\
$\alpha\left(\mathrm{m}^{-1}\right)$ & 3.28 & 0.46 & 38.3 \\
$b$ & 4.05 & 11.4 & 2.89 \\
$\theta_{w}\left(\mathrm{~m}^{3} \mathrm{~m}^{-3}\right)$ & 0.166 & 0.402 & 0.194 \\
$\Delta \theta\left(\mathrm{m}^{3} \mathrm{~m}^{-3}\right)$ & 0.102 & 0.037 & 0.176 \\
\hline
\end{tabular}

In the study here we have selected soils from the data set of Clapp and Hornberger (1978) with the properties as given in Thornburn et al. (2003). The two extremes in this data set, sand and clay, were chosen. A further soil, (BB10) from the set of soils of Verburg et al. (2001) which was used by Thorburn et al. (2003) in their study, was also chosen for its extreme value of $\alpha$. The properties of these soils are shown in Table 1. The initial condition was chosen as the water content when the matric potential was $-10.24 \mathrm{~m}$ and calculated using eqn (7)

\subsection{Analytical Model}

For given values of the soil properties and $Q$ of $1.65 \mathrm{~L} \mathrm{hr}^{-1}$, values of $(R, \phi)$ were obtained by solving eqns (1) and (4) iteratively, to obtain the wetted perimeter. The values of the wetted perimeter at 1 and 4 hours $(1.65$ and $6.6 \mathrm{~L}$ of applied water) will be used here. These irrigation application times (volumes of water) equate to a range likely to be applied on a daily basis in trickle irrigation systems. The wetting front, radius in the plane of the source, the depth below the source and, for buried soil, the height of the above source were obtained from the perimeter data.

\subsection{Numerical Model}

In HYDRUS2D it is not possible to have a point source with the source strength required to give the flow rate used in this study. Hence a region on the boundary with a constant flux on the surface or centred at $1 \mathrm{~m}$ depth for the buried emitter was used. The domain size was chosen to be $1 \mathrm{~m}$ radius by $2 \mathrm{~m}$ depth. In none of the simulations did the wetting front intersect any of the domain boundaries. For the buried emitter a curved boundary condition was chosen, as this is more realistic. However, as will be discussed later this results in a difficulty when comparing the results with a point source.

By trial and error the length of the constant flux boundary and flux were chosen to give the required flow rate and provide a stable solution of the problem. Obtaining a stable solution was particularly difficult for the clay soil.

The water content contours were obtained by matching the nodal spatial data with the water content data at each time. This data manipulation was performed using spreadsheets. HYDRUS2D does have a graphic interface that provides a visual representation of the water content contours, but it is not possible to put this in the format required for this publication.

\section{Results and Discussion}




\subsection{Buried Emitter}

The wetting front for a buried source calculated with either the analytical or numerical models were similar for the clay (Figure 1) and sand (Figure 2) soils. However, for BB10 soil the results with HYDRUS2D showed a much greater symmetry about the emitter than the analytical model (Figure 3). This is unlikely to be due to the size of the cavity used in HYDRUS2D, as this was the same for the sand soil with $\rho=0.02 \mathrm{~m}$.

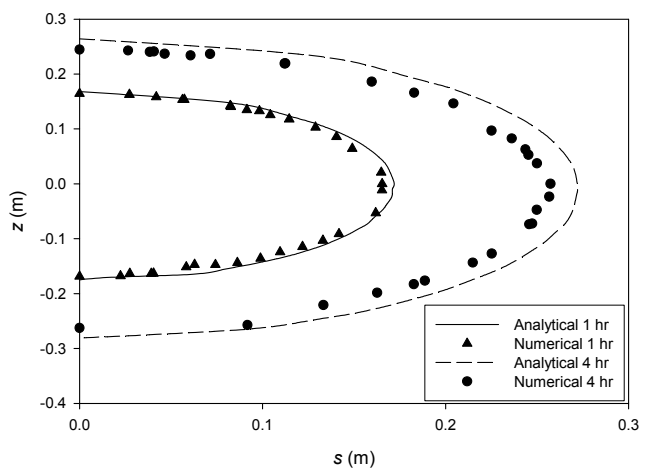

Figure 1. Contour lines for the wetting perimeter for a clay soil calculated with HYDRUS2D and eqn (1) at 1 hour and 4 hours.

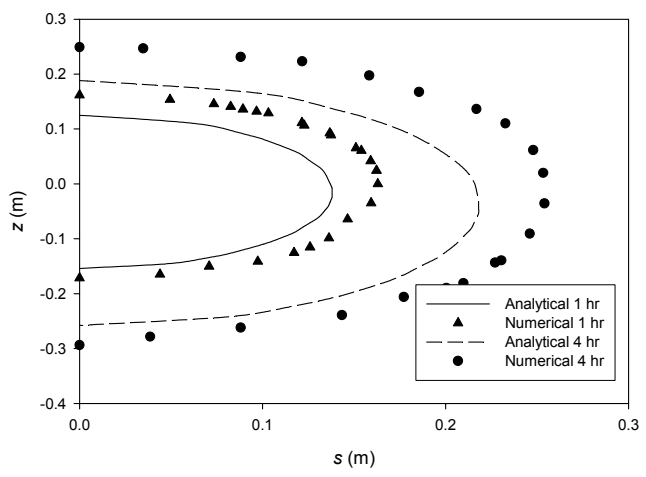

Figure 2. Contour lines for the wetting perimeter for a sand soil calculated with HYDRUS2D and eqn (1) at 1 hour and 4 hours.

The reason for this discrepancy may be due to the very large $\alpha$ of 38.3 for this soil. This results in a very rapid reduction in hydraulic conductivity with water content if $k$ is calculated with eqn (6) and eqn (7). The water content at the wetting front was calculated with the Brooks and Corey functions, eqn (8).

The difference in water content resulting from the use of these different hydraulic

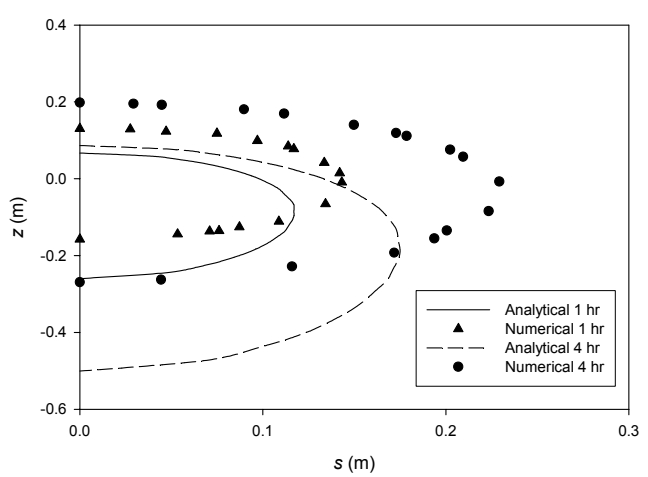

Figure 3. Contour lines for the wetting perimeter for a BB10 soil calculated with HYDRUS2D and eqn (1) at 1 hour and 4 hours.

conductivity functions at a wetting front hydraulic conductivity of $1 \mathrm{~mm} /$ day is shown in Figure 4. There is almost no difference for the sand soil, some difference for the clay soil and a large difference for BB10. The value for $\theta_{w}$ at the wetting front is underestimated using eqn (8) compared with eqn (6). If eqn (6) had been used a lower value of $\Delta \theta$ would have resulted and depth of wetting would have been greater. Thus the different hydraulic models do not explain the difference in depth of wetting between the analytical and numerical models.

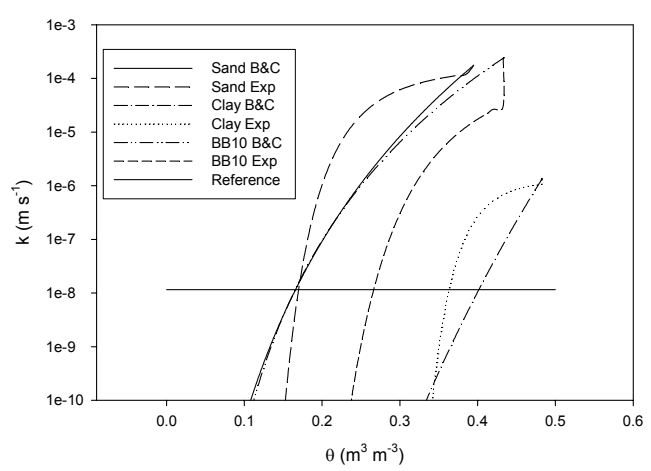

Figure 4. Hydraulic conductivity $(k)$ calculated with either eqn (5) (Exp) or eqn (7). The horizontal line is $k=1 \mathrm{~mm} /$ day.

A large value of $\alpha$ suggests that gravitational forces in the soil dominate over capillary forces, a view supported by the results shown in Figure 3. These results also suggest that for soils with high values of $\alpha$ for buried emitters the analytical model may overestimate the wetting depth below the emitter and underestimate the wetting above the emitter. 
However, further investigations are required to resolve why this occurs.

\subsection{Surface Emitter}

For the surface emitter with the clay soil HYDRUS2D results in a greater amount of radial spread compared to analytical model after $1 \mathrm{hr}$ of wetting (Figure 5).

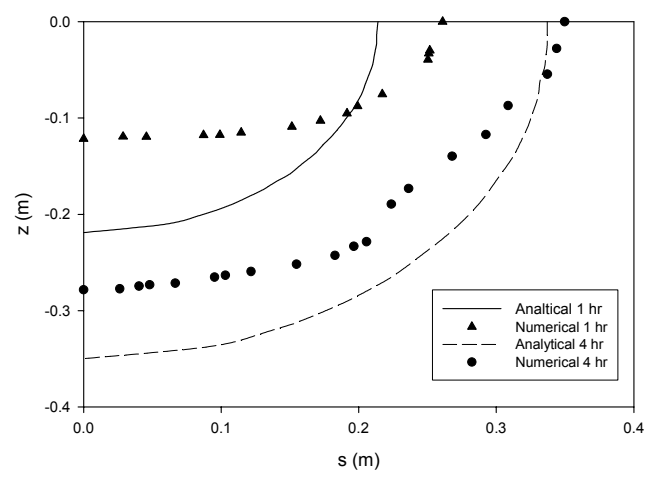

Figure 5. Contour lines for the wetting perimeter for a clay soil calculated with HYDRUS2D and eqn (4) at 1 hour and 4 hours.

This is due to the inflow zone on the upper boundary needing to be quite large for the clay soil $(\rho=0.215 \mathrm{~m})$, to prevent numerical instabilities. By the time 4 hours are reached the wetting fronts are similar for HYDRUS2D and analytical models for the clay.

In the sand soil the inflow zone on the upper boundary was quite small $(\rho=0.015 \mathrm{~m})$, and so even at 1 hour the two models gave similar wetting front positions (Figure 6). The wetting front positions are similar after 4 hours suggesting that both models will give similar results in soils with properties similar to the sand.

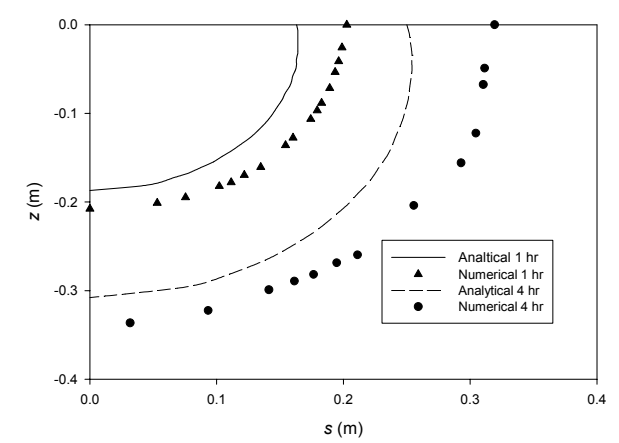

Figure 6. Contour lines for the wetting perimeter for a sand soil calculated with HYDRUS2D and eqn (4) at 1 hour and 4 hours.
For a surface emitter the BB10 soil gave similar results to the buried emitter with the analytical model suggesting the wetting front would penetrate deeper than HYDRUS2D (Figure 7). Also, the analytical model suggests that the maximum radius would occur at some depth below the surface, which HYDRUS2D did not reproduce. This again is due to the effect of the high value of $\alpha$ on the flow regime in the analytical model.

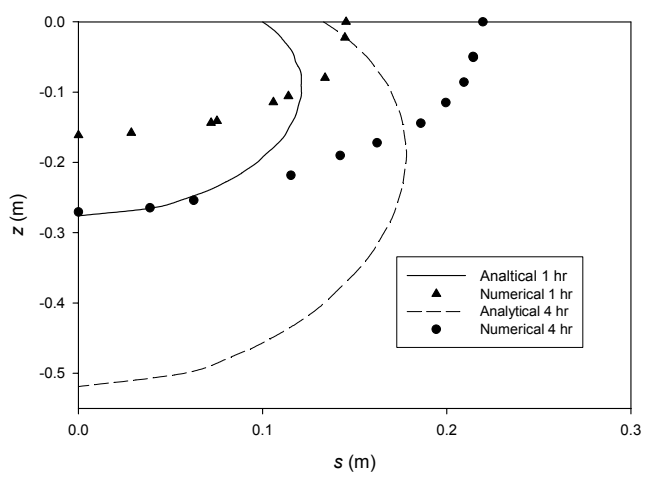

Figure 7. Contour lines for the wetting perimeter for a BB10 soil calculated with HYDRUS2D and eqn (4) at 1 hour and 4 hours.

Obtaining results with HYDRUS2D proved to be difficult in the clay soil due to numerical instability problems. Under such circumstances a considerable amount of 'art' is required to get a results. Given that the analytical model gave similar results this suggests that results with this model may be adequate except in soils with high values of $\alpha$.

\section{Conclusions}

Wetting front patterns generated with either an analytical and numerical model (HYDRUS2D) were shown to give similar results for buried and surface emitters except when the soil had an unusually high value of $\alpha$.

For soils with high values of $\alpha$ the analytical model may exaggerate the depth of wetting. Although as yet the reasons are not clear.

HYDRUS2D proved difficult to operate in the clay soil due to numerical instability problems. In such soils the radial spreading at early times is overestimated. 


\section{References}

Bristow, K.L., J.W. Hopmans, C.M. Cote, P. B.Charlesworth, P.J. Thorburn, and F.J. Cook, Development of improved water and nutrient management strategies through strategic modelling. Paper Presented at Internation Union od Soil Science, $17^{\text {th }}$ World Congress. Bangkok, Thailand, August, 14-21, 2002.

Brooks, R.H. and A.T. Corey, Properties of porous media affecting fluid flow. Journal of the Irrigation and Drainage Division, 2, 61-88, 1966.

Campbell, G.S., A simple method for determining unsaturated conductivityfrom moisture retention data. Soil Science, 117, 311-314, 1974.

Charlesworth, P.B., C., Chinn, K.L Bristow, and G. Ham, (2002) Healthy crop and healthy groundwater sugarcane in the Burdekin delta. IAA National - Conserve or Conflict, Sydney Exhibition Centre, May 22-24

Clapp R.B. and G.M. Hornberger, Empirical equations for soil hydraulic properties. Water Resources Research 14, 601-604, 1978

Cook F.J., P.J. Thorburn, K.L. Bristow, and C.M. Cote, Infiltration from surface and buried point sources: The average wetting water content. Water Resources Research (In Prep.) 2003

Cote C.M., K.L. Bristow, P.B. Charlesworth, F.J. Cook, and P.J. Thorburn, Analysis of soil wetting and solute transport in sub-surface trickle irrigation. In: Thorburn P.J., K.L. Bristow, and J. Annandale (eds) Micro-irrigation: Advances in system design and management. Irrigation Science (In Press) 2003

Gardner, W.R., Calculation of capillary conductivity from pressure plate outflow data. Soil Science Society of America Proceedings, 20, 317-320, 1956.

Phene C.J., Research trends in microirrigation. In: Lamm FR (ed.) Microirrigation for a changing world: Conserving resources/preserving the environment. Proceedings of the Fifth International Microirrigation Congress, Orlando, Florida, USA, 2-6 April, 1995. ASAE, St. Joseph, Michigan, pp 6-24.

Philip J.R., Travel times from buried and surface infiltration points sources. Water Resources Research 20, 990-994, 1984
Philip J.R., Reply to "Comments on 'Steady infiltration from spherical cavities"” Soil Science Society of America Journal 49, 788, 1985.

Raats P.A.C., and W.R. Gardner, Comparison of empirical relationships between pressure head and hydraulic conductivity and some observations on radially symmetrical flow. Water Resources Research 7, 921-925,1971

Revol P., B.E. Clothier, J.C. Mailhol, G Vachaud, and M. Vauclin, Infiltration from a surface point source and drip irrigation. 2. An approximate timedependent solution for wet-front position. Water Resources Research 33, 1869-1874,1997

Simunek, J., M. Sejna and M.Th. van Genuchten, , HYDRUS-2D /

MESHGEN-2D: Simulating water flow and solute transport in two-dimensional variably saturated media. International Groundwater Modeling Centre, Colorado School of Mines, Golden, Colorado, 1999.

Thorburn P.J., F.J. Cook, and K.L. Bristow () Soil-dependent wetting from trickle emitters: Implications for trickle design and management. In: Thorburn P.J., Bristow, K.L., and J. Anandale (eds) Micro-irrigation: Advances in system design and management. Irrigation Science, (In Press), 2003

Verburg K., B.J. Bridge, K.L. Bristow, and B.A. Keating, Properties of selected soils in the Gooburrum - Moore Park area of Bundaberg. Technical Report 09/01, CSIRO Land and Water, Canberra, Australia, 2001

White, I. And M.J. Sully, Macroscopic and microscopic capillary length and time scales from field infiltration. Water Resources Research 23, 1514-1522, 1987.

Waterloo Maple Inc,. Maple 7 Programming Guide. p 628, 2001 